\title{
Investigation of the Atomic Structure of Ge-Sb-Se Chalcogenide Glasses
}

\author{
M. Fabian $\mathbb{D}^{1,2}$ N. Dulgheru, ${ }^{3}$ K. Antonova, ${ }^{4}$ A. Szekeres, ${ }^{4}$ and M. Gartner ${ }^{3}$ \\ ${ }^{1}$ Centre for Energy Research, Hungarian Academy of Sciences, H-1525 Budapest P.O.B. 49, Hungary \\ ${ }^{2}$ Wigner Research Centre for Physics, Hungarian Academy of Sciences, H-1525 Budapest P.O.B. 49, Hungary \\ ${ }^{3}$ Institute of Physical Chemistry "Ilie Murgulescu", Romanian Academy, 202 Splaiul Independentei, 060021 Bucharest, Romania \\ ${ }^{4}$ Institute of Solid State Physics, Bulgarian Academy of Sciences, Tzarigradsko Chaussee 72, 1784 Sofia, Bulgaria
}

Correspondence should be addressed to M. Fabian; fabian.margit@energia.mta.hu

Received 16 July 2018; Revised 21 September 2018; Accepted 30 October 2018; Published 2 December 2018

Academic Editor: Jörg Fink

Copyright (c) 2018 M. Fabian et al. This is an open access article distributed under the Creative Commons Attribution License, which permits unrestricted use, distribution, and reproduction in any medium, provided the original work is properly cited.

\begin{abstract}
Glasses with composition of $\mathrm{Ge}_{\mathrm{x}} \mathrm{Sb}_{40-\mathrm{x}} \mathrm{Se}_{60}(\mathrm{x}=40,35,32,27,20,15$ at. \%) have been synthesized. Neutron and X-ray diffraction techniques were used to study the atomic glassy structure, and Reverse Monte Carlo (RMC) simulations were applied to model the 3-dimensional atomic configurations and thorough mapping of the atomic parameters, such as first and second neighbour distances, coordination numbers, and bond-angle distributions. The results are explained with formation of $\mathrm{GeSe}_{4}$ and $\mathrm{SbSe}_{3}$ structural units, which correlate with the Ge/Sb ratio. For all the studied compositions, the Ge-Se, Sb-Se, Ge-Ge, and Se-Se bonds are significant. RMC simulations reveal the presence of $\mathrm{Ge}-\mathrm{Sb}$ and $\mathrm{Sb}-\mathrm{Sb}$ bonds, being dependent on $\mathrm{Ge} / \mathrm{Sb}$ ratio. All atomic compositions satisfy formal valence requirements, i.e., Ge is fourfold coordinated, Sb is threefold coordinated, and Se is twofold coordinated. By increasing the Sb content, both the Se-Ge-Se bonds angle of $107 \pm 3^{\circ}$ and Se-Sb-Se bonds angle of $118 \pm 3^{\circ}$ decrease, respectively, indicating distortion of the structural units. Far infrared Fourier Transform spectroscopic measurements conducted in the range of $50-450 \mathrm{~cm}^{-1}$ at oblique $\left(75^{\circ}\right)$ incidence radiation have revealed clear dependences of the IR band's shift and intensity on the glassy composition, showing features around $\mathrm{x}=27$ at.\% supporting the topological phase transition to a stable rigid network consisting mainly of $\mathrm{SbSe}_{3}$ pyramidal and $\mathrm{GeSe}_{4}$ tetrahedral clusters. These results are in agreement with the Reverse Monte Carlo models, which define the Ge and $\mathrm{Sb}$ environment.
\end{abstract}

\section{Introduction}

In recent years a great deal of interest has been devoted to the optical studies of chalcogenide glasses because of their wide area of applications as electrical and optical components as well as optical fibers in the infrared optical region, which are the basis of many applications [1-4]. Ternary Ge$\mathrm{Sb}$-Se glasses are promising materials for infrared optical fibers application because of their high transparency in the key region and good thermal, mechanical, and chemical properties. The physicochemical, elastic-plastic, and optical properties of the ternary $\mathrm{Ge}$-Sb-Se chalcogenide system have been intensively studied [5-13], and the influence of $\mathrm{Ge} / \mathrm{Sb}$ ratio on the optical, electronic, and microstructural properties of Ge-Sb-Se system has been considered. A common and useful parameter for the explanation of the compositional dependence on the physical properties is the coordination number $\mathrm{Z}$ of covalent bonds per atom, characterizing the structural atomic units $[5,13,14]$. For the compositions under investigation, a value of $Z=2.65-2.67$ corresponding to $x=25$ 27 at.\% has been obtained as critical for a transition from 2D cross-linked chains arrangements to formation of 3D network of tetrahedral $\mathrm{GeSe}_{4}$ and pyramidal $\mathrm{SbSe}_{3}$ when the $\mathrm{x}$ value increases $[5,13]$.

Still one of the main questions remains how the structure of Ge environment changes, when the Ge atoms are replaced by $\mathrm{Sb}$ atoms. A comprehensive answer can be obtained by combining different methods and techniques, such as neutron diffraction (ND), high-energy X-ray diffraction (XRD), and far infrared (IR) Fourier Transform spectroscopy, which offers comprehensive information about the atomic structure. In addition, theoretical modeling of such experimental 
results using Reverse Monte Carlo (RMC) method allows building three-dimensional structure models and, thus, obtaining a more detailed description of the atomic-scale glassy structure. In connection with this, we have successfully performed experiments combining the ND and XRD techniques and RMC simulation method for the study of ternary As-Se-Te [15] and quaternary Ge-Sb-S(Se)-Te glasses [16-18]. Using the experience gained, we have started to investigate new Ge-Sb-Se system. The compositional dependence of the structure and physical and optical properties of ternary Ge$\mathrm{Sb}$-Se system is of interest, especially considering the effects of average coordination number, $Z$, of covalent bonds per atom.

In this paper, we focused on the atomic-scale structure characterization of nonstoichiometric $\mathrm{Ge}_{\mathrm{x}} \mathrm{Sb}_{40-\mathrm{x}} \mathrm{Se}_{60}$ compositions, where $x$ varied between 15 and 40 at. \%. For examining the alteration of the glassy structure with changes in composition, we applied an approach in which ND and high-energy XRD techniques with Reverse Monte Carlo (RMC) modeling were combined. The procedure of RMC modeling is considered in details in Section 3.1. By this way, characteristic parameters, such as structure factors, partial atomic pair correlation functions, coordination numbers, and bond-angle distribution functions, are established. Recently, the chemical short order in $\mathrm{Ge}_{20} \mathrm{Sb}_{\mathrm{x}} \mathrm{Se}_{80-\mathrm{x}}(\mathrm{x}=5,15,20)$ compositions has been studied by the nuclear techniques and extended X-ray absorption fine structure measurements [19] as one of the compositions, namely, $\mathrm{Ge}_{20} \mathrm{Sb}_{20} \mathrm{Se}_{40}$, is among the compositions we study herein. Our results obtained by the combination of different methods would widen the knowledge about these materials and would contribute to a better understanding of the structural changes by composition.

In addition, we performed Fourier Transform infrared (FTIR) reflectance measurements in the terahertz spectral range in order to get more information about the microstructure and basic chemical bonding of the studied compositions. So far, few far IR spectral measurements have been carried out for studying the long-wavelength multiphonon edge of these materials. Raman and FTIR spectra have been reported in [5] and [8, 10, 20, 21], respectively, as in the latter PE pellets are used resulting in a not so good spectrum even when they are converted in absorption units. To avoid this, we carried out the FTIR measurements on thin $(\sim 1 \mu \mathrm{m})$ films deposited on quartz substrates. Using incidence radiation under a large angle of $75^{\circ}$ the obtained spectra are more informative about the composition microstructure with variation of $x$ value. The results of this paper correspond to the conclusions presented by other authors and are in agreement with our earlier publications [5] on bulk samples served here as parent materials for thin films preparation.

\section{Experimental Section}

2.1. Sample Preparation. The binary $\mathrm{Ge}_{40} \mathrm{Se}_{60}$ and ternary $\mathrm{Ge}_{\mathrm{x}} \mathrm{Sb}_{40-\mathrm{x}} \mathrm{Se}_{60}$ glasses with $\mathrm{x}=15,20,27,32$, and 35 at. \% were prepared from elements of $99.999 \%$ purity. Appropriate quantities from $\mathrm{Ge}, \mathrm{Se}$, and $\mathrm{Sb}$ were sealed into quartz ampoules after evacuation down to a pressure of $10^{-3} \mathrm{~Pa}$. The bulk glasses were synthesized by the conventional meltquenching method in a rotary furnace at $950^{\circ} \mathrm{C}$. After

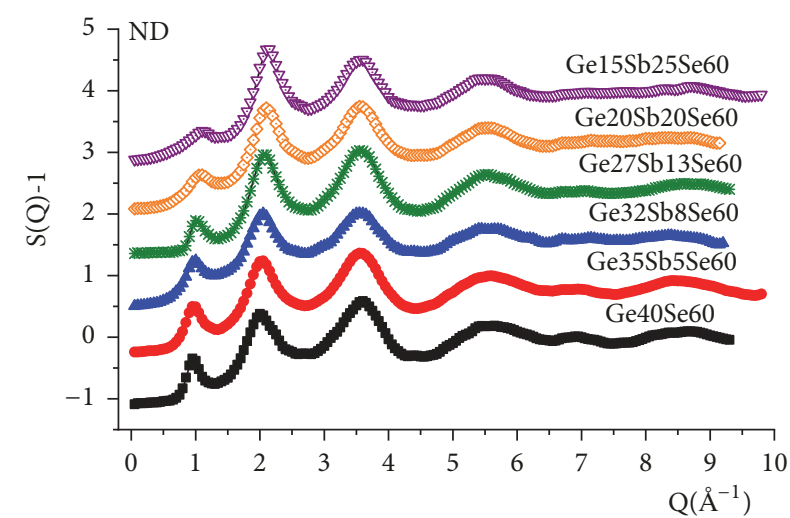

FIGURE 1: Neutron diffraction structure factor, $S(Q)$, of the chalcogenide samples with composition of $\mathrm{Ge}_{\mathrm{x}} \mathrm{Sb}_{40-\mathrm{x}} \mathrm{Se}_{60}(\mathrm{x}=40,35,32,27$, 20,15 at.\%) is displayed: experimental data (colour marks) and RMC simulation (solid lines). For better clarity, the curves are shifted vertically.

homogenization for $24 \mathrm{~h}$, the melts were quenched in air.

Part of the bulk samples was powdered. At the ND and $\mathrm{XRD}$ studies, powdered material was used as specimen with $\sim 3 \mathrm{~g}$ /each composition. The powdered glasses served also as parent material at evaporation of thin films for Fourier Transform infrared (FTIR) spectroscopic studies.

The thin films were deposited onto quartz substrates by vacuum thermal evaporation of the powders from the corresponding parent $\mathrm{Ge}_{\mathrm{x}} \mathrm{Sb}_{40-\mathrm{x}} \mathrm{Se}_{60}$ materials at a residual pressure of $10^{-4} \mathrm{~Pa}$ in the chamber. The thickness of the films $(\sim 1 \mu \mathrm{m})$ was controlled in situ by MIKI FFV quartz sensor device.

2.2. Neutron and X-Ray Diffraction Experiments. The neutron diffraction measurements were performed at room temperature in the 2-axis 'PSD' monochromatic neutron diffractometer $\left(\lambda_{0}=1.068 \AA ; Q=0.45-9.8 \AA^{-1}\right)$ [22] at the 10 MW Budapest Research Reactor, using thermal neutrons. The powder specimens ( $\sim 3 \mathrm{~g} /$ each $)$ were filled in cylindrical vanadium sample holder of $8 \mathrm{~mm}$ diameter. The structure factors, $S(Q)$, were evaluated from the raw experimental data. The overall run of the ND experimental curves is similar for the investigated samples, but characteristic differences especially in the low Q-range can be observed. Figure 1 presents the $S(Q)$ from neutron diffraction experiments, where the results of the Reverse Monte Carlo model calculation are also drawn, but this will be discussed later, in Section 3 .

The X-ray diffraction experiments were carried out at the beam line BW5 at HASYLAB, DESY [23]. The powdered samples were filled into quartz capillary tubes of $2 \mathrm{~mm}$ in diameter (wall thickness of $\sim 0.02 \mathrm{~mm}$ ) and measured at room temperature. The energy of the radiation was $109.5 \mathrm{keV}$ $\left(\lambda_{0}=0.113 \AA\right)$. The high-energy synchrotron X-ray radiation makes it possible to reach diffraction data up to high- $Q$ values. In this study the XRD structure factors were obtained up to $18 \AA^{-1}$, as for higher $Q$-values the experimental data became rather noisy. Because the atomic parameters of the 
TABLE 1: Neutron and X-ray diffraction weighting factors, $w_{\mathrm{ij}}(\%)$ at $Q=1.05 \AA^{-1}$, of the partial atomic pairs in $\mathrm{Ge}_{15} \mathrm{Sb}_{25} \mathrm{Se}_{60} \operatorname{sample}$

\begin{tabular}{|c|c|c|c|c|c|}
\hline \multicolumn{6}{|c|}{$\mathrm{Ge}_{15} \mathrm{Sb}_{25} \mathrm{Se}_{60}$} \\
\hline Ge-Ge & Ge-Sb & Ge-Se & Sb-Sb & Sb-Se & Se-Se \\
\hline \multicolumn{6}{|c|}{ ND weighting factor (\%) } \\
\hline 2.75 & 6.24 & 21.43 & 3.54 & 24.30 & 41.74 \\
\hline \multicolumn{6}{|c|}{ XRD weighting factor (\%) at $Q=1.05 \AA^{-1}$} \\
\hline 1.59 & 8.49 & 13.56 & 11.32 & 36.16 & 28.88 \\
\hline
\end{tabular}

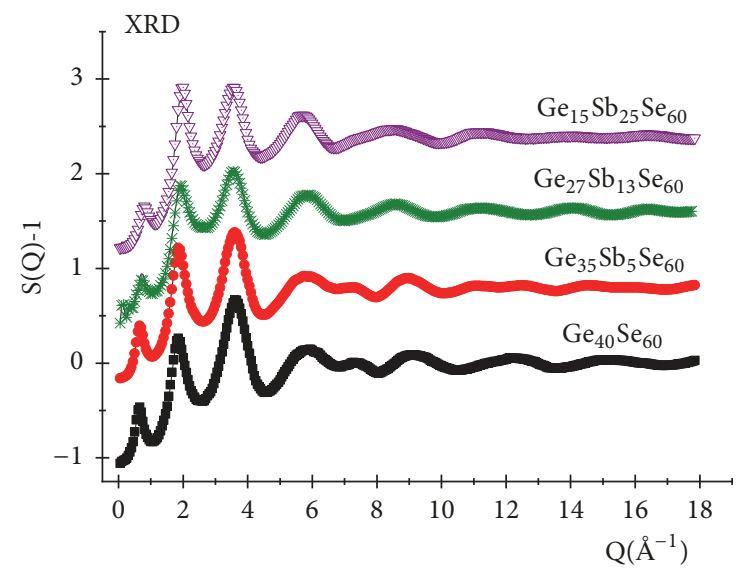

Figure 2: X-ray diffraction structure factor, $S(Q)$, of the ternary $\mathrm{Ge}_{\mathrm{x}} \mathrm{Sb}_{40-\mathrm{x}} \mathrm{Se}_{60}$ with composition of $\mathrm{x}=35,27,15$ at. $\%$ and the binary $\mathrm{Ge}_{40} \mathrm{Se}_{60}$ glasses is displayed: experimental data (colour marks) and RMC simulation (solid lines). For better clarity, the curves are shifted vertically.

components are similar, the XRD structure factors were similar to ND ones. We consider here the XRD data for four samples which shows well the concentration dependence within the series. The XRD experimental $S(Q)$ data together with the RMC simulation results (details of the RMC modeling will be discussed in Section 3) are presented in Figure 2.

The shape and character of the ND (Figure 1) and XRD (Figure 2) structure factors testify to a fully amorphous glassy structure in nature. However, there are some fine differences between the ND and XRD spectra. The differences in the overall run of these spectra lie in the different values of the weighting factors, $w_{i j}$, of the partial structure factors, $S_{i j}(Q)$, defined as

$$
\begin{gathered}
S(Q)=\sum_{i, j}^{k} w_{i j} S_{i j}(Q), \\
w_{i j}^{N D}=\frac{c_{i} c_{j} b_{i} b_{j}}{\left[\sum_{i, j}^{k} c_{i} b_{j}\right]^{2}}, \\
w_{i j}^{X R D}(Q)=\frac{c_{i} c_{j} f_{i}(Q) f_{j}(Q)}{\left[\sum_{i, j}^{k} c_{i} f_{i}(Q)\right]^{2}},
\end{gathered}
$$

where $c_{i}, c_{j}$ are the molar fractions of the components, $b_{i}$, $b_{j}$ are the coherent neutron and $f_{i}(Q), f_{j}(Q)$ are the Xray scattering amplitudes, and $k$ is the number of elements in the sample. For the binary $\mathrm{Ge}_{40} \mathrm{Se}_{60}$ sample $k$ is 2 , thus $k(k+1) / 2=3$, and for the ternary Ge-Sb-Se samples $\mathrm{k}$ is 3 , thus $k(k+1) / 2=6$, and, therefore, 6 different atom pairs are present in the studied series. The neutron scattering amplitude of an element is constant in the entire Q-range [24], while the Xray scattering amplitude is $Q$-dependent [25] and for each atom it differs in a somewhat different way. To illustrate the differences, the comparison of the corresponding weighting factors, $w_{i j}$, for the two radiations is shown in Table 1 , where $w_{i j}^{N D}$ and $w_{i j}^{X R D}(Q)$ at $Q=1.05 \AA^{-1}$ are given for the $\mathrm{Ge}_{15} \mathrm{Sb}_{25} \mathrm{Se}_{60}$ sample.

It can be seen that the Ge-Se and Se-Se atom pairs have a significant contribution in the neutron experiment, while the $\mathrm{Sb}-\mathrm{Sb}$ and $\mathrm{Sb}-\mathrm{Se}$ atom pairs have a dominant weight in the $\mathrm{X}$ ray experiment. On the other hand, the differences appeared for the $\mathrm{Ge}-\mathrm{Ge}$ and $\mathrm{Ge}-\mathrm{Sb}$ atom pairs are not more significant than those for the other ones. Taking into consideration all these characteristics, we have concluded that the two radiations give complementary information, and both types of measurements are needed to obtain a real structure for the investigated samples.

2.3. Fourier Transform Infrared Spectrophotometry. In order to detect the basic chemical bonding in the $\mathrm{Ge}_{\mathrm{x}} \mathrm{Sb}_{40-\mathrm{x}} \mathrm{Se}_{60}$ compositions Fourier Transform infrared measurements were performed in the terahertz spectral range of $450-50 \mathrm{~cm}^{-1}$ of the polarized light. FTIR spectra were measured in close to reflectance-absorbance geometry with an incident radiation angle of $75^{\circ}$, permitting maximal optical path through the sample. A Bruker Vertex 70 instrument and a reflectance accessory Bruker A513/Q were used. The resolution was 2 $\mathrm{cm}^{-1}$ and the number of scans was 100. A gold standard mirror was used for the spectral normalization.

\section{Results and Discussion}

3.1. Reverse Monte Carlo Simulation. The experimental diffraction $S(Q)$ data has been simulated by the RMC method [26], which is a widely used effective tool to model disordered structures. The RMC minimizes the squared difference between the experimental $S(Q)$ and the calculated one from a $3 \mathrm{D}$ atomic configuration. From the RMC configuration the partial pair correlation functions, $\left(g_{i j}(r)\right)$, the coordination numbers, and the bond-angle distributions were calculated using the software package $\mathrm{RMC}^{++}$[27].

In order to investigate the possible effect of the starting configuration on the results, the following model was built 
TABLE 2: Cut-off distances ( $\AA$ ) for atom pairs used in the final RMC run.

\begin{tabular}{|c|c|c|c|c|c|c|}
\hline \multirow[t]{2}{*}{ Atom pairs } & \multicolumn{6}{|c|}{ Cut-off distances $(\AA)$} \\
\hline & $\mathrm{Ge}_{40} \mathrm{Se}_{60}$ & $\mathrm{Ge}_{35} \mathrm{Sb}_{5} \mathrm{Se}_{60}$ & $\mathrm{Ge}_{32} \mathrm{Sb}_{8} \mathrm{Se}_{60}$ & $\mathrm{Ge}_{27} \mathrm{Sb}_{13} \mathrm{Se}_{60}$ & $\mathrm{Ge}_{20} \mathrm{Sb}_{20} \mathrm{Se}_{60}$ & $\mathrm{Ge}_{15} \mathrm{Sb}_{25} \mathrm{Se}_{60}$ \\
\hline Ge-Se & 2.15 & 2.05 & 2.15 & 2.15 & 2.10 & 2.125 \\
\hline $\mathrm{Sb}-\mathrm{Se}$ & - & 2.10 & 2.125 & 2.15 & 2.175 & 2.17 \\
\hline $\mathrm{Ge}-\mathrm{Sb}$ & - & 2.25 & 2.25 & 2.20 & 2.25 & 2.25 \\
\hline $\mathrm{Ge}-\mathrm{Ge}$ & 2.30 & 2.20 & 2.20 & 2.20 & 2.20 & 2.25 \\
\hline Se-Se & 2.00 & 2.20 & 2.20 & 2.15 & 2.15 & 2.175 \\
\hline Sb-Sb & - & 2.35 & 2.35 & 2.345 & 2.35 & 2.30 \\
\hline
\end{tabular}

up. The initial configuration was generated by random distribution of 10000 atoms in a cubic simulation box. The experimentally measured density was $0.032,0.030,0.031$, $0.038,0.039$, and 0.038 atoms $/ \AA^{3}$ [28] corresponding to box edges of $31.90 \AA, 34.66 \AA, 34.29 \AA, 32.05 \AA, 31.76 \AA$, and 32.05 $\AA$ for the $\mathrm{Ge}_{40} \mathrm{Se}_{60}, \mathrm{Ge}_{35} \mathrm{Sb}_{5} \mathrm{Se}_{60}, \mathrm{Ge}_{32} \mathrm{Sb}_{8} \mathrm{Se}_{60}, \mathrm{Ge}_{27} \mathrm{Sb}_{13} \mathrm{Se}_{60}$, $\mathrm{Ge}_{20} \mathrm{Sb}_{20} \mathrm{Se}_{60}$, and $\mathrm{Ge}_{15} \mathrm{Sb}_{25} \mathrm{Se}_{60}$ samples, respectively.

The Ge, Sb, and Se elements possess comparable neutron and X-ray scattering amplitudes, which makes it rather difficult to identify the atomic positions. In order to avoid unreasonable short-range orders for all atom pairs, in the RMC simulation procedure constraints were applied to the minimum interatomic distances between atom pairs (cutoff distances). The starting cut-off distances were taken from the previous studies for the similar contents $[15,17]$ and from the literature based on the results of similar or very close glassy compositions [29, 30]. Several RMC runs have been performed by modifying slightly the cutoff distances for each atom pairs. The final cut-off distances, used further in the RMC modeling, are summarized in Table 2. From our previous study and from literature data, we expect that the main glassy network is built up by the $\mathrm{GeSe}_{4 / 2}$ tetrahedra and the $\mathrm{SbSe}_{3 / 2}$ pyramid units. Therefore, it is suggested that the atomic structure of the ternary glasses is built up by chain connection of $\mathrm{GeSe}_{4 / 2}$ tetrahedra and $\mathrm{SbSe}_{3 / 2}$ pyramid through a 2-coordinated Se atoms. Thus, the 4-coordinated Ge unit connects through a Se atom to a 3-coordinated $\mathrm{Sb}$ unit and, therefore, the first neighbour distance of $\mathrm{Ge}-\mathrm{Sb}$ is less realistic. In the literature, there are studies [29, 31-33], which support this suggestion. Considering the values of the weighting factors in Table 1, one can see that Ge-Sb bond's weighting factors $\left(w_{\mathrm{ND}, \mathrm{Ge}-\mathrm{Sb}}=6.24 \%\right.$ and $\left.w_{\mathrm{XRD}, \mathrm{Ge}-\mathrm{Sb}}=8.49 \%\right)$ are lower than those for Ge-Se $\left(w_{\mathrm{ND}, \mathrm{Ge}-\mathrm{Se}}=21.43 \%\right.$ and $\left.w_{\mathrm{XRD}, \mathrm{Ge}-\mathrm{Se}}=13.56 \%\right)$ and $\mathrm{Sb}-\mathrm{Se}\left(w_{\mathrm{ND}, \mathrm{Sb}-\mathrm{Se}}=24.30 \%\right.$ and $\left.w_{\mathrm{XRD}, \mathrm{Sb}-\mathrm{Se}}=36.16 \%\right)$, which bonds have well known first neighbour distances. From these follows that $\mathrm{Ge}-\mathrm{Sb}$ bonds most probably have the second neighbour distance. Nevertheless, in the RMC modeling, we did not exclude any first neighbour distances and Figure 3 presents all partial pair correlation functions obtained from the RMC calculations.

The experimental structure factors $(S(Q))$ are compared with those accumulated from the data of the RMC models of the corresponding glass compositions. For each sample, close to 20 RMC configurations were obtained in the intervals of more than 1500000 accepted moves of atoms inside of the simulation box. Good agreement between the experimental and calculated diffraction data was achieved. The comparison between the experimental and calculated structure factors are illustrated in Figures 1 and 2. The measured neutron diffraction data in Figure 1 shows significant dependence on the composition, especially at low- $Q$ values. For all compositions, the first and the most intensive peaks were situated at 1.1 and $2.1 \AA^{-1}$, while the next less intensive ones are at $3.55 \AA^{-1}$ and at $5.5 \AA^{-1}$. Figure 2 displays the XRD $S(Q)$ spectra, where the first intensive peak is observed at $0.6 \AA^{-1}$, a second intensive peak at $1.8 \AA^{-1}$, and two other broaden and much less intensive peaks at $3.5 \AA^{-1}$ and at $5.7 \AA^{-1}$.

In order to get comprehensive structural information about the studied series, we have investigated all homopolar and heteropolar atomic distances. The partial atomic pair correlation functions, $g_{\mathrm{ij}}(r)$, were revealed from the RMC simulation with a good reproducibility and acceptable statistics. The obtained partial pair distribution functions are presented in Figure 3. The first peaks are well defined and, thus, we could perform an unambiguous evaluation of distances.

It was found that $\mathrm{Ge}-\mathrm{Se}, \mathrm{Sb}-\mathrm{Se}, \mathrm{Ge}-\mathrm{Ge}$, and $\mathrm{Se}-\mathrm{Se}$ bonds are significant in the studied samples. The peaks related to the first interatomic distances appear at $2.35 \pm 0.01 \AA$, $2.54 \pm 0.01 \AA, 2.47 \pm 0.03 \AA$, and $2.32 \pm 0.02 \AA$, respectively, as these peaks appear at the same position within the error for all the studied compositions. Because of the allowed cutoff distances (Table 2), first interatomic distances between $\mathrm{Ge}-\mathrm{Sb}$ and $\mathrm{Sb}-\mathrm{Sb}$ atoms were found at $2.55 \pm 0.05 \AA$ and $2.57 \pm 0.03 \AA$, but the corresponding first peak's intensity was very low (Figures 3(c) and 3(e)). This suggests that second neighbour distance between $\mathrm{Ge}$ and $\mathrm{Sb}$ is more realistic. Second characteristic peaks were obtained for $\mathrm{Ge}-\mathrm{Sb}, \mathrm{Ge}-\mathrm{Ge}$, $\mathrm{Sb}-\mathrm{Sb}$, and Se-Se atom pairs, which are displayed at 3.80 \pm 0.05 $\AA$, $3.85 \pm 0.05 \AA, 3.80 \pm 0.05 \AA$, and $3.80 \pm 0.05 \AA$, respectively.

The partial atomic pair correlation functions are summarized in Table 3. These values, with exceptions of Ge-Sb and Ge-Ge, are close to the data given in [19], but the differences could be due to the annealing of samples in that work, which altered their glassy structure.

The great advance of the RMC method is that the coordination number, $C N_{\mathrm{ij}}$, can be obtained from the final particle configurations. From the partial pair distribution functions we calculated the number of nearest neighbours for $\mathrm{Ge}, \mathrm{Sb}$, and Se atoms using the corresponding bond cut-off distances. 


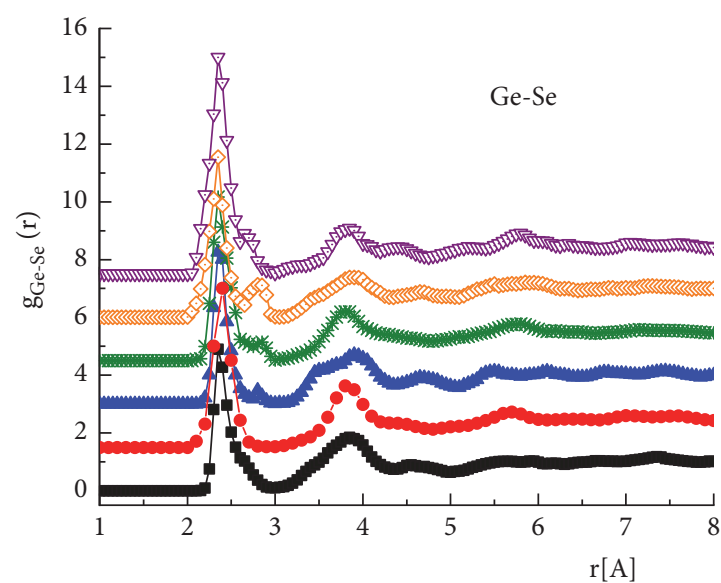

(a)

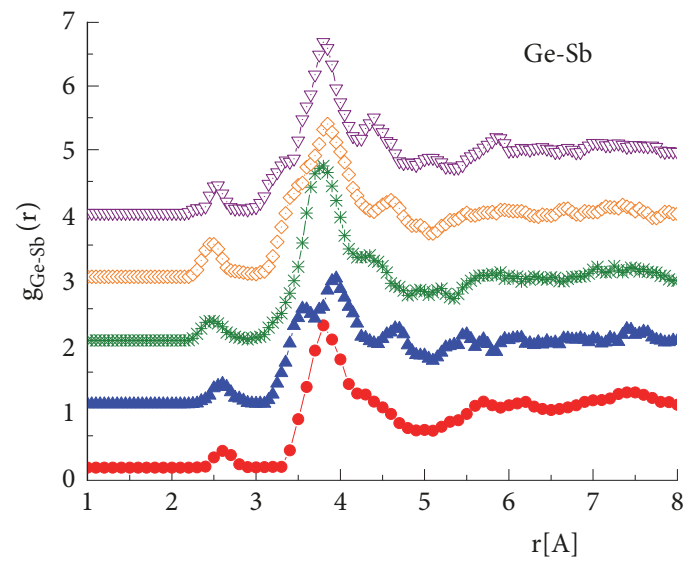

(c)

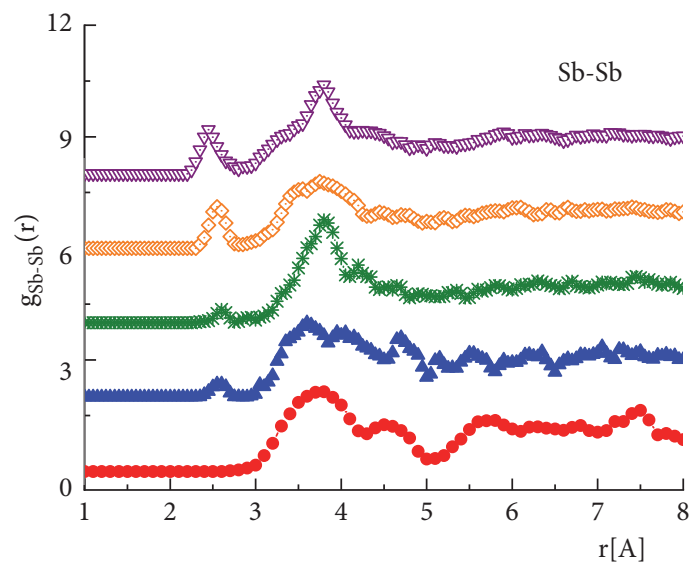

(e)

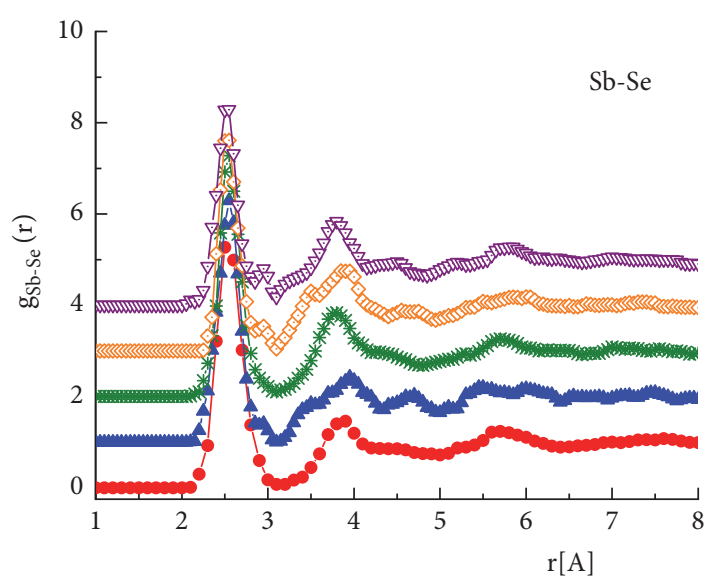

(b)

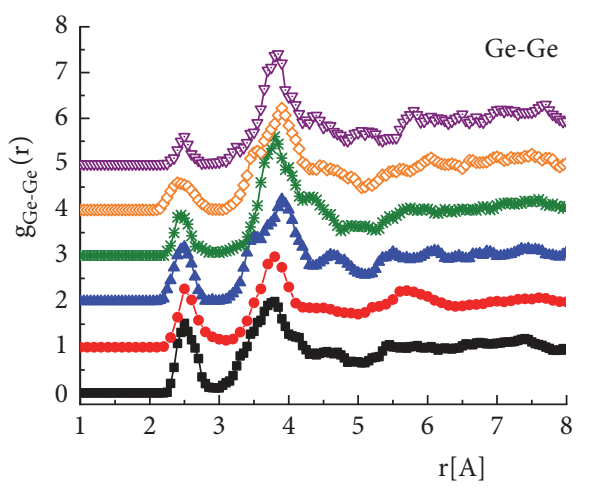

(d)

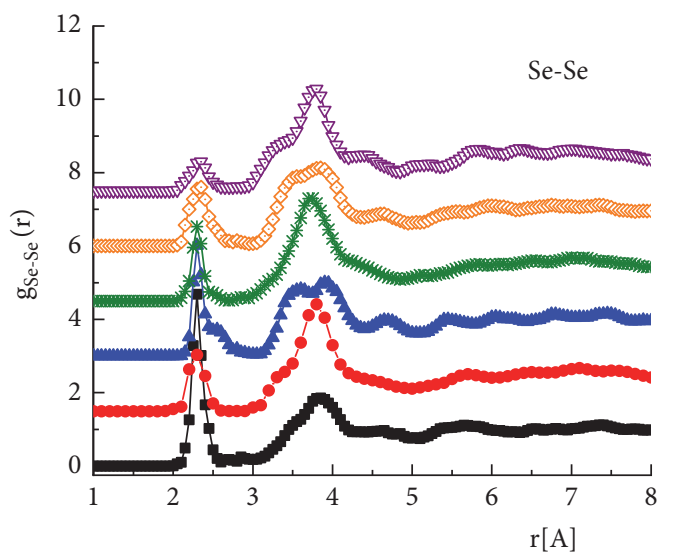

(f)

Figure 3: Partial atom pair correlation functions, $g_{\mathrm{ij}}(r)$ for the $\mathrm{Ge}_{40} \mathrm{Se}_{60}$ (black square), $\mathrm{Ge}_{35} \mathrm{Sb}_{5} \mathrm{Se}_{60}$ (red circle), $\mathrm{Ge}_{32} \mathrm{Sb}_{8} \mathrm{Se}_{60}$ (blue triangle), $\mathrm{Ge}_{27} \mathrm{Sb}_{13} \mathrm{Se}_{60}$ (green crosses), $\mathrm{Ge}_{20} \mathrm{Sb}_{20} \mathrm{Se}_{60}$ (orange square), and $\mathrm{Ge}_{15} \mathrm{Sb}_{25} \mathrm{Se}_{60}$ (purple reverse triangle) compositions, obtained by RMC modeling of the Ge-Se (a), Sb-Se (b), Ge-Sb (c), Ge-Ge (d), Sb-Sb (e), and Se-Se (f) atom pairs. For better clarity, the curves are shifted vertically.

It is necessary to specify the range of $r$ within which atoms are counted as neighbours and which determine the coordination shells. We introduced the quantities $r_{1}$ and $r_{2}$, where $r_{1}$ and $r_{2}$ are the positions of minimum values on the lower and upper side of the corresponding peaks, respectively. From the literature, we know some details related to the coordination numbers of the present atoms: concerning the Ge atoms, they are 4-coordinated, the $\mathrm{Sb}$ atoms are 3-coordinated, and Se atoms expected to be close to 2-coordinated sites. To obtain more information about the atomic structure, we carried out 
TABLE 3: Interatomic distances, $r_{\mathrm{ij}}(\AA)$, in chalcogenide samples obtained from the RMC simulation.

\begin{tabular}{|c|c|c|c|c|c|c|}
\hline \multirow{2}{*}{ Atom pairs } & \multicolumn{6}{|c|}{ Interatomic distances, $r_{\mathrm{ij}}(\AA)$} \\
\hline & $\mathrm{Ge}_{40} \mathrm{Se}_{60}$ & $\mathrm{Ge}_{35} \mathrm{Sb}_{5} \mathrm{Se}_{60}$ & $\mathrm{Ge}_{32} \mathrm{Sb}_{8} \mathrm{Se}_{60}$ & $\mathrm{Ge}_{27} \mathrm{Sb}_{13} \mathrm{Se}_{60}$ & $\mathrm{Ge}_{20} \mathrm{Sb}_{20} \mathrm{Se}_{60}$ & $\mathrm{Ge}_{15} \mathrm{Sb}_{25} \mathrm{Se}_{60}$ \\
\hline Ge-Se & $2.34 / 3.85 \pm 0.02$ & $2.35 / 3.82 \pm 0.02$ & $2.36 / 3.90 \pm 0.02$ & $2.35 / 3.80 \pm 0.02$ & $2.35 / 3.85 \pm 0.02$ & $2.35 / 3.82 \pm 0.02$ \\
\hline $\mathrm{Sb}-\mathrm{Se}$ & - & $2.54 / 3.88 \pm 0.02$ & $2.55 / 3.90 \pm 0.05$ & $2.55 / 3.80 \pm 0.02$ & $2.53 / 3.90 \pm 0.02$ & $2.55 / 3.80 \pm 0.03$ \\
\hline $\mathrm{Ge}-\mathrm{Sb}$ & - & $2.60 / 3.80 \pm 0.05$ & $2.60 / 3.55 / 3.80 \pm 0.05$ & $2.50 / 3.80 \pm 0.05$ & $2.50 / 3.85 \pm 0.05$ & $2.52 / 3.80 \pm 0.05$ \\
\hline Ge-Ge & $2.50 / 3.80 \pm 0.02$ & $2.50 / 3.80 \pm 0.02$ & $2.47 / 3.90 \pm 0.03$ & $2.45 / 3.80 \pm 0.02$ & $2.45 / 3.90 \pm 0.03$ & $2.50 / 3.80 \pm 0.02$ \\
\hline Se-Se & $2.30 / 3.85 \pm 0.02$ & $2.30 / 3.80 \pm 0.05$ & $2.30 / 3.60 / 3.90 \pm 0.05$ & $2.30 / 3.75 \pm 0.05$ & $2.30 / 3.83 \pm 0.05$ & $2.33 / 3.80 \pm 0.05$ \\
\hline Sb-Sb & - & $3.80 / 4.35 \pm 0.05$ & $2.57 / 3.85 \pm 0.05$ & $2.60 / 3.80 \pm 0.05$ & $2.60 / 3.75 \pm 0.05$ & $2.55 / 3.80 \pm 0.05$ \\
\hline
\end{tabular}

TABLE 4: Average coordination numbers, $C N_{\mathrm{ij}}$, calculated from the RMC simulation. In brackets are indicated the intervals of $r$ within which the atoms are counted as neighbours and, thus, the actual coordination numbers are calculated. The error is $\sim 5 \%$ for $\mathrm{Ge}-\mathrm{Se}$, $\mathrm{Sb}-\mathrm{Se}, \mathrm{Se}-\mathrm{Ge}$ and $\sim 10 \%$ for Ge-Sb, Sb-Ge, Se-Sb, Ge-Ge, Sb-Sb, Se-Se. The total coordination distributions are signed by Ge-X for Ge, Sb-X for Sb, and Se-X for Se atom.

\begin{tabular}{|c|c|c|c|c|c|c|}
\hline \multirow{2}{*}{ Atom pairs } & \multicolumn{6}{|c|}{ Coordination Number, $C N_{\mathrm{ij}}$} \\
\hline & $\mathrm{Ge}_{40} \mathrm{Se}_{60}$ & $\mathrm{Ge}_{35} \mathrm{Sb}_{5} \mathrm{Se}_{60}$ & $\mathrm{Ge}_{32} \mathrm{Sb}_{8} \mathrm{Se}_{60}$ & $\mathrm{Ge}_{27} \mathrm{Sb}_{13} \mathrm{Se}_{60}$ & $\mathrm{Ge}_{20} \mathrm{Sb}_{20} \mathrm{Se}_{60}$ & $\mathrm{Ge}_{15} \mathrm{Sb}_{25} \mathrm{Se}_{60}$ \\
\hline Ge-Se & $\begin{array}{c}2.97 \\
\left(r_{1}: 2.15-r_{2}: 2.90\right) \\
\end{array}$ & $\begin{array}{c}3.10 \\
\left(r_{1}: 2.2-r_{2}: 2.85\right) \\
\end{array}$ & $\begin{array}{c}3.22 \\
\left(r_{1}: 2.15-r_{2}: 2.8\right) \\
\end{array}$ & $\begin{array}{c}3.45 \\
\left(r_{1}: 2.15-r_{2}: 2.95\right) \\
\end{array}$ & $3.63\left(r_{1}: 2.15-r_{2}: 2.95\right)$ & $3.84\left(r_{1}: 2.1-r_{2}: 2.9\right)$ \\
\hline Ge-Sb & 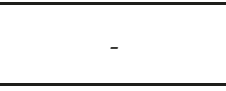 & $\begin{array}{c}0.05 \\
\left(r_{1}: 2.4-r_{2}: 2.85\right) \\
\end{array}$ & $\begin{array}{c}0.02 \\
\left(r_{1}: 2.4-r_{2}: 2.8\right) \\
\end{array}$ & $\begin{array}{c}0.03 \\
\left(r_{1}: 2.2-r_{2}: 2.75\right) \\
\end{array}$ & $0.05\left(r_{1}: 2.3-2.75\right)$ & $0.07\left(r_{1}: 2.3-r_{2}: 2.7\right)$ \\
\hline $\mathrm{Sb}-\mathrm{Se}$ & - & $\begin{array}{c}2.97 \\
\left(r_{1}: 2.2-r_{2}: 3.0\right) \\
\end{array}$ & $\begin{array}{c}2.80 \\
\left(r_{1}: 2.15-r_{2}: 3.1\right) \\
\end{array}$ & $\begin{array}{c}2.78 \\
\left(r_{1}: 2.15-r_{2}: 3.0\right) \\
\end{array}$ & $2.64\left(r_{1}: 2.2-r_{2}: 2.95\right)$ & $2.59\left(r_{1}: 2.15-r_{2}: 3.0\right)$ \\
\hline $\mathrm{Sb}-\mathrm{Ge}$ & - & $\begin{array}{c}0.03 \\
\left(r_{1}: 2.4-r_{2}: 2.85\right) \\
\end{array}$ & $\begin{array}{c}0.05 \\
\left(r_{1}: 2.4-r_{2}: 2.8\right) \\
\end{array}$ & $\begin{array}{c}0.04 \\
\left(r_{1}: 2.2-r_{2}: 2.75\right) \\
\end{array}$ & $0.09\left(r_{1}: 2.3-r_{2}: 2.75\right)$ & $0.11\left(r_{1}: 2.3-r_{2}: 2.7\right)$ \\
\hline Se-Ge & $\begin{array}{c}1.98 \\
\left(r_{1}: 2.15-r_{2}: 2.90\right) \\
\end{array}$ & $\begin{array}{c}1.81 \\
\left(r_{1}: 2.2-r_{2}: 2.85\right) \\
\end{array}$ & $\begin{array}{c}1.72 \\
\left(r_{1}: 2.15-r_{2}: 2.8\right) \\
\end{array}$ & $\begin{array}{c}1.55 \\
\left(r_{1}: 2.15-r_{2}: 2.95\right)\end{array}$ & $1.21\left(r_{1}: 2.2-r_{2}: 2.85\right)$ & $0.96\left(r_{1}: 2.1-r_{2}: 2.9\right)$ \\
\hline $\mathrm{Se}-\mathrm{Sb}$ & ch & $\begin{array}{c}0.21 \\
\left(r_{1}: 2.2-3.0\right) \\
\end{array}$ & $\begin{array}{c}0.31 \\
\left(r_{1}: 2.15-3.1\right) \\
\end{array}$ & $\begin{array}{c}0.58 \\
\left(r_{1}: 2.15-3.0\right)\end{array}$ & $0.88\left(r_{1}: 2.15-2.95\right)$ & $1.08\left(r_{1}: 2.15-3.0\right)$ \\
\hline Ge-Ge & $\begin{array}{c}0.74 \\
\left(r_{1}: 2.25-r_{2}: 2.90\right) \\
\end{array}$ & $\begin{array}{c}0.55 \\
\left(r_{1}: 2.2-r_{2}: 2.95\right) \\
\end{array}$ & $\begin{array}{c}0.52 \\
\left(r_{1}: 2.15-r_{2}: 2.8\right) \\
\end{array}$ & $\begin{array}{c}0.40 \\
\left(r_{1}: 2.2-r_{2}: 2.8\right) \\
\end{array}$ & $0.23\left(r_{1}: 2.2-r_{2}: 2.8\right)$ & $0.05\left(r_{1}: 2.25-r_{2}: 2.75\right)$ \\
\hline Sb-Sb & - & 0.00 & $\begin{array}{c}0.03 \\
\left(r_{1}: 2.35-r_{2}: 2.75\right) \\
\end{array}$ & $\begin{array}{c}0.02 \\
\left(r_{1}: 2.45-r_{2}: 2.75\right)\end{array}$ & $0.3\left(r_{1}: 2.35-r_{2}: 2.85\right)$ & $0.15\left(r_{1}: 2.2-r_{2}: 2.75\right)$ \\
\hline $\mathrm{Se}-\mathrm{Se}$ & $\begin{array}{c}0.04 \\
\left(r_{1}: 2.1-r_{2}: 2.6\right) \\
\end{array}$ & $\begin{array}{c}0.02 \\
\left(r_{1}: 2.1-r_{2}: 2.65\right) \\
\end{array}$ & $\begin{array}{c}0.02 \\
\left(r_{1}: 2.15-r_{2}: 2.6\right) \\
\end{array}$ & $\begin{array}{c}0.03 \\
\left(r_{1}: 2.15-r_{2}: 2.6\right) \\
\end{array}$ & $0.05\left(r_{1}: 2.1-r_{2}: 2.65\right)$ & $0.08\left(r_{1}: 2.1-r_{2}: 2.6\right)$ \\
\hline Ge-X & 3.71 & 3.69 & 3.76 & 3.88 & 3.91 & 3.96 \\
\hline Sb-X & - & 3.00 & 2.88 & 2.84 & 2.85 & 2.85 \\
\hline Se-X & 2.02 & 2.02 & 2.05 & 2.16 & 2.14 & 2.12 \\
\hline
\end{tabular}

constrained simulations, in which $\mathrm{Ge}$ and $\mathrm{Sb}$ atoms were forced to have four and three neighbours, respectively. The corresponding average coordination numbers, $C N_{\mathrm{ij}}$, obtained from the RMC simulations, are tabulated in Table 4. The coordination numbers show a clear dependence with the $\mathrm{Ge} / \mathrm{Sb}$ ratio. The results suggest the presence of two basic structural units, namely, the $\mathrm{GeSe}_{4}$ tetrahedral units with fourfold coordinated $\mathrm{Ge}$ atom and $\mathrm{SbSe}_{3}$ pyramids with threefold coordinated $\mathrm{Sb}$ atom.

In Figure 4 the average coordination number distributions of the possible chemical bonds, calculated from the RMC modeling, are presented. It can be seen that the average coordination number around $\mathrm{Ge}$ atoms is close to four atoms, as is expected by the formation of tetrahedral units in the network.
However, with increasing Sb content the Ge-Se coordination number, $C N_{\mathrm{Ge}-\mathrm{Se}}$, slightly increases from 3.10 to 3.84 atoms, which indicates a small degree of angle distortion affecting the tetrahedral surrounding. This may be caused by the formation of Se-Ge bonds, as the coordination of Se atoms increases from 2.02 to 2.16 . The average $C N_{\mathrm{Ge}-\mathrm{X}}$ coordination number increases from 3.69 to 3.96 with increasing $\mathrm{Sb}$ content. This suggests that the chalcogenide network consists of stable tetrahedral Ge units. The $C N_{\mathrm{Sb}-\mathrm{Se}}$ coordination number continuously decreases from 2.97 to 2.50 with increasing $\mathrm{Sb}$ concentration. The $\mathrm{Sb}-\mathrm{X}$ average coordination number slightly varied from 3.00 to 2.85 . The Se-Ge coordination number continuously decreases from 1.98 to 0.96 with increasing $\mathrm{Sb}$ concentration, while the $\mathrm{Se}-\mathrm{Sb}$ coordination number increases from 0.21 to 1.08 ; 


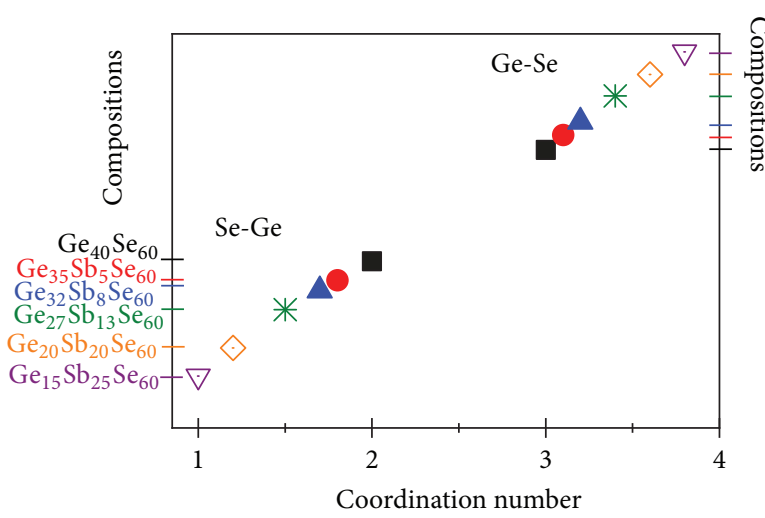

(a)

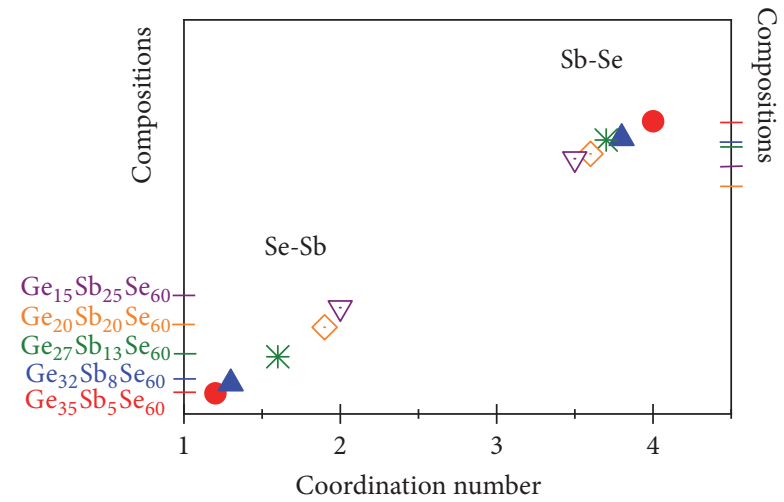

(b)

Figure 4: Coordination number distributions, $C_{\mathrm{ij}}$, for the Ge-Se and Se-Ge bonds (a) and Sb-Se and Se-Sb bonds (b) in the corresponding compositions of $\mathrm{Ge}_{40} \mathrm{Se}_{60}$ (black square), $\mathrm{Ge}_{35} \mathrm{Sb}_{5} \mathrm{Se}_{60}$ (red circle), $\mathrm{Ge}_{32} \mathrm{Sb}_{8} \mathrm{Se}_{60}$ (blue triangle), $\mathrm{Ge}_{27} \mathrm{Sb}_{13} \mathrm{Se}_{60}$ (green crosses), Ge $\mathrm{Ge}_{20} \mathrm{Sb}_{20} \mathrm{Se}_{60}$ (orange square), and $\mathrm{Ge}_{15} \mathrm{Sb}_{25} \mathrm{Se}_{60}$ (purple reverse triangle).

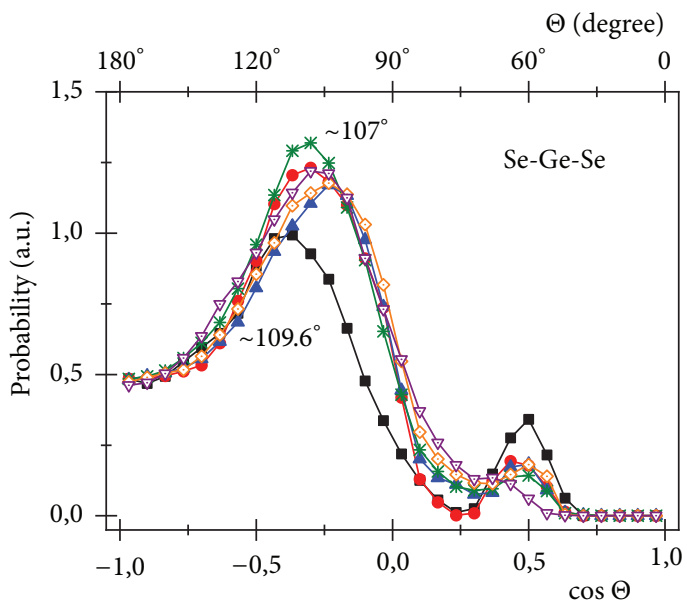

(a)

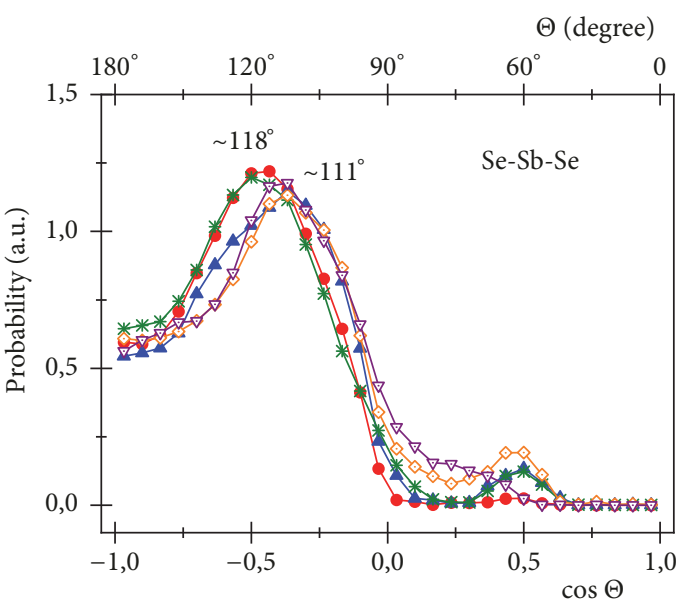

(b)

FIGURE 5: Bond-angle distributions of Se-Ge-Se (a) and Se-Sb-Se (b) configurations for the corresponding compositions of Ge $\mathrm{Ge}_{40} \mathrm{Se}_{60}$ (black square), $\mathrm{Ge}_{35} \mathrm{Sb}_{5} \mathrm{Se}_{60}$ (red circle), $\mathrm{Ge}_{32} \mathrm{Sb}_{8} \mathrm{Se}_{60}$ (blue triangle), $\mathrm{Ge}_{27} \mathrm{Sb}_{13} \mathrm{Se}_{60}$ (green crosses), $\mathrm{Ge}_{20} \mathrm{Sb}_{20} \mathrm{Se}_{60}$ (orange square), and $\mathrm{Ge}_{15} \mathrm{Sb}_{25} \mathrm{Se}_{60}$ (purple reverse triangle).

nevertheless, the concentration of Se atoms is kept constant.

Figure 5 shows the bond-angle distributions for the Ge and $\mathrm{Sb}$ atoms with $\mathrm{Se}-\mathrm{Ge}-\mathrm{Se}$ and $\mathrm{Se}-\mathrm{Sb}-\mathrm{Se}$ three-particle bond angles. We calculated the three-particle bond-angle distributions using the final atomic configuration of the RMC algorithm, plotted both as the function of $\cos (\Theta)$ (scale below) and $\Theta$ (upper scale), where $\Theta$ represents the actual bond angle.

For the Se-Ge-Se bonds, the peak positions are at $107 \pm 3^{\circ}$ (for the ternary samples) [in agreement with [34]] and at $109.6 \pm 2^{\circ}$ (for the binary sample) [35] which are very close to the tetrahedral angle of $109.47^{\circ}$. The peak distribution is very similar for all the studied samples. The broad distribution is quite asymmetric, but with the increase of $\mathrm{Sb}$ concentration, a shift down can be observed suggesting that the tetrahedral environment has become distorted. The distribution of Se$\mathrm{Sb}$-Se bonding angles is broad and asymmetric, the average angles being $118 \pm 3^{\circ}$ and $111 \pm 5^{\circ}$. The broad distribution suggests that 3 -fold $\mathrm{Sb}$ atoms are present. The Se-Sb-Se bond angles distribution also shows similar characteristics for all samples, as with the increase of $\mathrm{Sb}$ concentration a shift down to the $111 \pm 5^{\circ}$ can be observed implying considerable distortion in $\mathrm{Sb}_{3}$ planar geometry. In most of the cases, a weak peak around $60 \pm 3^{\circ}$ appears, strongly dependent on glassy composition, which is due to the occasional presence of threefold rings [35].

The present RMC simulation of the ND and XRD data points out that the $\mathrm{Sb}$ atoms incorporated in $\mathrm{Ge}_{40} \mathrm{Se}_{60}$ glass bind covalently to Se and form $\mathrm{SbSe}_{3}$ - trigonal units. On the other hand, Se atoms, which are also connected to Ge, form $\mathrm{GeSe}_{4}$ tetrahedral structural units. These findings are in agreement with several spectroscopic studies $[5,8,36]$.

The atomic parameters support the formation of Getetrahedral and Sb-trigonal units in $\mathrm{Ge}_{40} \mathrm{Se}_{60}$ glass structure. When the $\mathrm{Sb}$ content gradually increases, strong Sb units are 


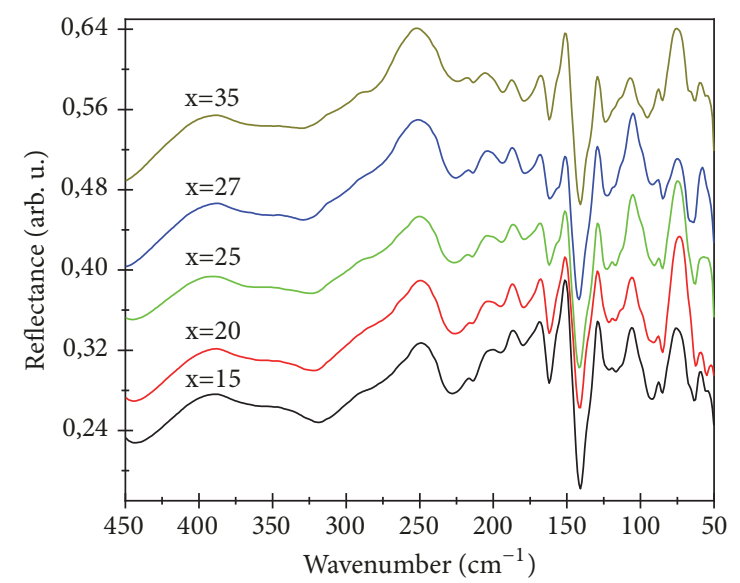

FIGURE 6: Far FTIR reflectance spectra of $\mathrm{Ge}_{\mathrm{x}} \mathrm{Sb}_{40-\mathrm{x}} \mathrm{Se}_{60}$ films at different $\mathrm{x}$ values.

formed with light influence of the tetrahedral Ge network, which causes only negligible changing of the partial pair distribution functions, coordination numbers, and bondangle distributions. The Ge-Sb bonds show a broad distribution at $3.8 \AA$, which suggests the existence of connection between Ge-tetrahedral and Sb-pyramidal units through Se atoms. Nevertheless, the Ge-Ge bonds indicate connections between the Ge-tetrahedral, even if in the literature only theoretical bonding is reported. Based on these findings we suppose that a few numbers of Ge-clusters exist, which are connected to the Sb-pyramids. From the values of bond lengths and coordination numbers, we can conclude that the network structure is constructed through connection of tetrahedral $\mathrm{GeSe}_{4}$ and trigonal $\mathrm{SbSe}_{3}$ structural units. The average coordination numbers vary with glassy composition, as it follows from Figure 4. In all the studied samples, the concentration of the Se atoms is constant. With increasing of $\mathrm{Sb}$ concentration, coordination of $\mathrm{Ge}$ atoms becomes close to 4 , while the coordination of $\mathrm{Sb}$ atoms becomes close to 3 , both coordination sites being close to theoretical ones. These results are in agreement with the literature and support formation of tetrahedral Ge and pyramidal Sb units $[19,29$, 37]. For the Se atoms, the coordination distribution changes in opposite direction, and with increasing of $\mathrm{Sb}$ concentration the Se-Ge coordination numbers decrease and the Se-Sb coordination numbers increase. This indicates that Se atom prefers to bind to $\mathrm{Sb}$ atom rather than $\mathrm{Ge}$ atom.

From the above considerations we can conclude that the changes in the distribution of the chemical bonds from the $\mathrm{Ge}_{\mathrm{x}} \mathrm{Sb}_{40-\mathrm{x}} \mathrm{Se}_{60}$ compositions with average coordination numbers $Z<2.67$ to the compositions with $Z>2.67$ are responsible for the structural rearrangement of the glassy network $[5,6,13]$

3.2. FTIR Spectra Analysis. The FTIR reflectance spectra in dependence on the index $x$ (Ge content) are presented in Figure 6 . They show considerably rich set of bands because unlike the crystal structure, the lack of symmetry in amorphous material changes the selection rules and, thus, some forbidden IR modes become active. The spectra present well pronounced reflectance-absorbance bands of collective lowfrequency vibrations. Although the spectral change with the Ge content is very small, there are bands which can be assigned to the vibrations affected by the $x$ variation.

The band at $250 \mathrm{~cm}^{-1}$ is characteristic for $\mathrm{Ge}_{\mathrm{x}} \mathrm{Se}_{100-\mathrm{x}}$ binary materials $[12,38]$. With increasing Ge and with introducing $\mathrm{Sb}$ in our $\mathrm{Ge}_{\mathrm{x}} \mathrm{Sb}_{40-\mathrm{x}} \mathrm{Se}_{60}$ samples the band becomes larger and more intensive. As we have already established that in $\mathrm{Ge}_{\mathrm{x}} \mathrm{Sb}_{40-\mathrm{x}} \mathrm{Se}_{60}$ glasses structural transformation occurs at $\mathrm{x}=25-27$ at.\% [6], we assume that $\mathrm{GeSe}_{2}$ and $\mathrm{GeSe}_{4}$ units coexist $[5,10,13]$ together with Se-Se bond vibration (shoulder at $288 \mathrm{~cm}^{-1}$ ) [8]. With increasing the Ge content and, respectively, decreasing the content of heavier $\mathrm{Sb}$ atoms, these bands move to shorter wavelengths, as seen in Figure 7, where a peculiarity appears at $\mathrm{x}=27$ at.\%, corresponding to an average coordination number of $\mathrm{Z}=2.67$.

The broad and structured band at $160-210 \mathrm{~cm}^{-1}$ is also sensitive to the $x$ variation. Its components at 168,187 , and 203 $\mathrm{cm}^{-1}$ are reduced in intensity by increasing the Ge content. In $[5,39]$ the authors have discussed Raman spectra in this spectral region assigning the measured frequencies to the dynamics of the tetrahedral $\mathrm{GeSe}_{4}$ vibrations with addition of $\mathrm{Sb}$ atoms and to the appearance of pyramidal $\mathrm{SbSe}_{3}$ vibrations. Moreover, the heteropolar Sb-Se and Ge-Se bonds vibrational modes have close position at $190 \mathrm{~cm}^{-1}$ and 200 $\mathrm{cm}^{-1}$, respectively $[5,38]$. The distinct peak around $168 \mathrm{~cm}^{-1}$ can be connected with formation of $\mathrm{Ge}-\mathrm{Ge}$ bonds by crosslinked $\mathrm{Ge}$ atoms in the $\mathrm{Ge}_{2} \mathrm{Se}_{6 / 2}$ chains ( $\mathrm{Se}_{3} \mathrm{Ge}-\mathrm{GeSe}_{3}$ units) $[5,40,41]$. We are convinced that these modes are responsible for forming the complex band as IR active due to the lack of symmetry in our amorphous samples, as it was obtained by FTIR transmission measurements in [10,21].

The band picked at $150 \mathrm{~cm}^{-1}$ with a shoulder at $157 \mathrm{~cm}^{-1}$ does not shift with $x$ but its intensity varies (see Figure 8). It could be related to the $\mathrm{Sb}$-Se (at small $x$ ) and to the Ge-Se (at higher $x$ ) nonsymmetric vibrations, respectively, $[8,21]$. At the highest value of $x=35$ at.\%, the band is slightly enlarged thus showing the coexistence of these vibrations.

The main bands in the terahertz range, $106 \mathrm{~cm}^{-1}$ and $74 \mathrm{~cm}^{-1}$, belong to the vibrations of $\mathrm{GeSe}_{4}$ tetrahedral and respectively to $\mathrm{SbSe}_{3}$ pyramidal units $[8,21]$. Because of these complex structures, they are surrounded with many weak peaks and shoulders. In Figure 8, it can be seen that the band intensities as function of $\mathrm{x}$ evolve in opposite directions, following the variation of the $\mathrm{Ge}$ and $\mathrm{Sb}$ content, respectively.

Bands in the FTIR spectra, located in the $250-320 \mathrm{~cm}^{-1}$ region (Figure 6) have very low intensity and a tendency to vanish by increasing the $\mathrm{Ge}$ at.\% and decreasing the $\mathrm{Sb}$ at.\%, respectively. They may be attributed to several vibrations of Se-Se, Ge-Ge, and Ge-Sb bonds in modified $\mathrm{GeSe}_{4}$ structural units $[21,38,41]$.

In the $450-350 \mathrm{~cm}^{-1}$ spectral range, a very broad band, centred at $420 \mathrm{~cm}^{-1}$ and with a weak shoulder around 340 $\mathrm{cm}^{-1}$, is observed. It is independent on the glassy composition and is related to vibration of oxygen impurity atoms in Ge$\mathrm{O}$ bonding $[42,43]$. The presence of oxygen-related impurity bonds in these Ge-Sb-Se films has been detected by infrared 


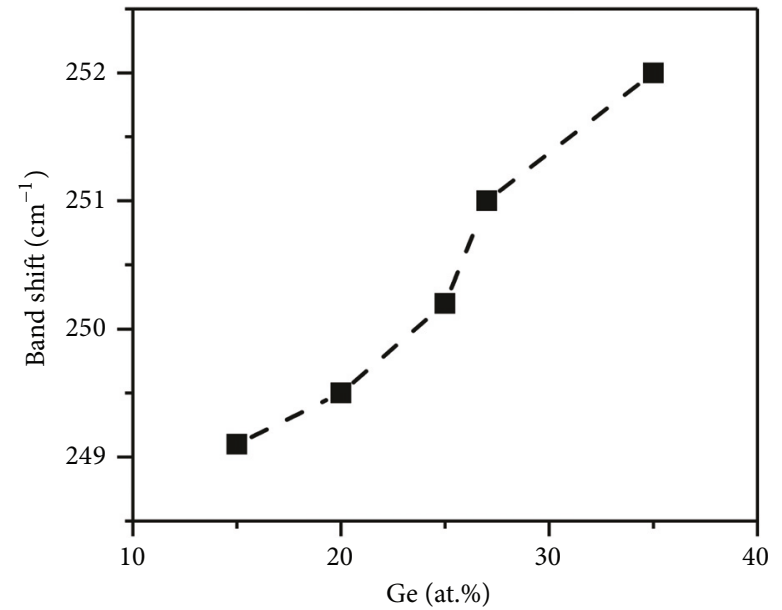

(a)

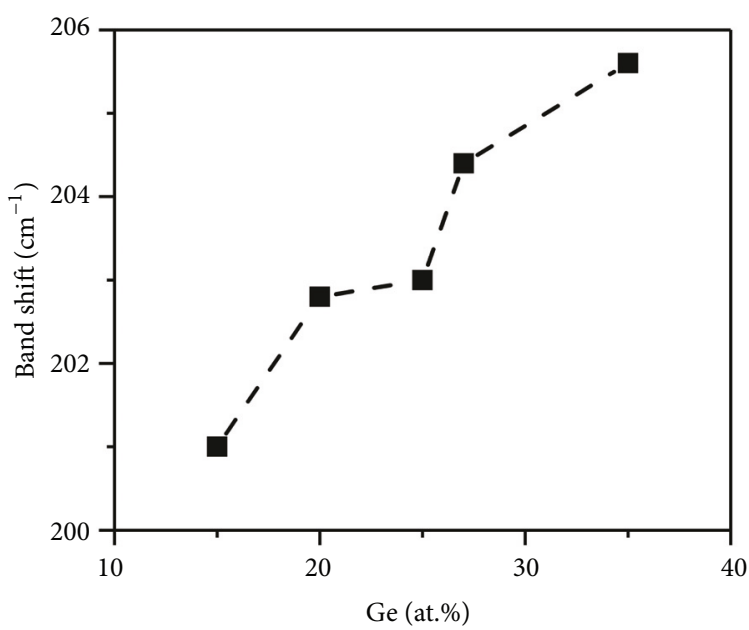

(b)

Figure 7: Shift of the bands at $250 \mathrm{~cm}^{-1}$ (a) and $200 \mathrm{~cm}^{-1}$ (b) with variation of $\mathrm{x}$ value.

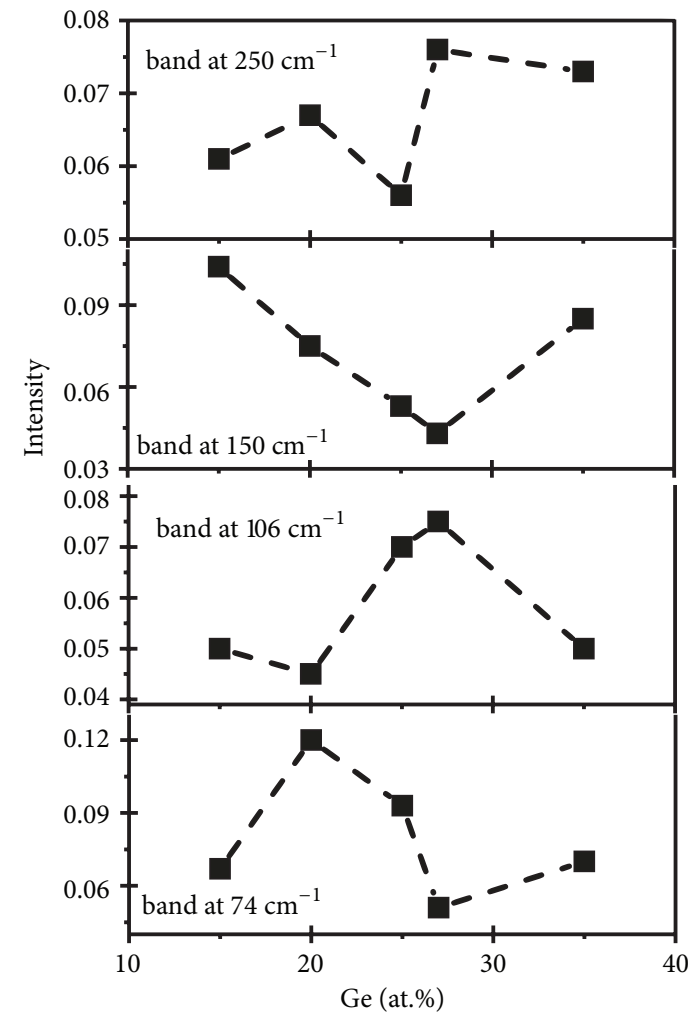

FIGURE 8: Dependence of bands intensity on the $\mathrm{x}$ values.

ellipsometric measurements performed in the 400- 4000 $\mathrm{cm}^{-1}$ spectral range [44].

From the study of the basic chemical bonds vibrational modes in chalcogenide $\mathrm{Ge}_{\mathrm{x}} \mathrm{Sb}_{40-\mathrm{x}} \mathrm{Se}_{60}$ films considering the FTIR reflection spectra at oblique $\left(75^{\circ}\right)$ incidence radiation, we obtained specific dependences of the band's shift and intensity on the film composition. Figures 7 and 8 show features around $\mathrm{x}=27$ at. $\%$, thus confirming the earlier published model of the topological phase transition to a stable rigid network consisting mainly of $\mathrm{SbSe}_{3}$ pyramidal and $\mathrm{GeSe}_{4}$ tetrahedral clusters. These results support the RMC modeling, which reveals that through connection of these $\mathrm{GeSe}_{4}$ and $\mathrm{SbSe}_{3}$ structural units, it is constructed a Ge-Sb-Se network structure.

\section{Conclusions}

Binary $\mathrm{Ge}_{40} \mathrm{Se}_{60}$ and ternary $\mathrm{Ge}_{\mathrm{x}} \mathrm{Sb}_{40-\mathrm{x}} \mathrm{Se}_{60}$ glasses with $\mathrm{x}=35$, $32,27,20$, and 15 at.\% compositions have been synthesized. Their structural properties have been investigated by neutron and X-ray diffraction measurements and RMC simulation procedures, in which all the possible chemical bonds in the glasses are taken into consideration. All specimens are fully amorphous in nature as confirmed by the ND and XRD patterns. It is revealed that addition of $\mathrm{Sb}$ atom to the binary $\mathrm{Ge}$ Se glass does not change significantly the basic Ge-tetrahedral structural units but leads to their distortion. With increasing of $\mathrm{Sb}$ concentration, well-defined Sb-pyramidal units are formed in the ternary glass structure. The $\mathrm{Ge}_{\mathrm{x}} \mathrm{Sb}_{40-\mathrm{x}} \mathrm{Se}_{60}$ glassy network builds up from $\mathrm{GeSe}_{4 / 2}$ tetrahedra and the $\mathrm{SbSe}_{3 / 2}$ pyramid units, connected through 2-coordinated Se atoms. Therefore, we may conclude that the "structural unit"based description of the RMC results is one possible way of interpreting the measured diffraction data.

The FTIR reflection spectra of chalcogenide $\mathrm{Ge}_{\mathrm{x}} \mathrm{Sb}_{40-\mathrm{x}} \mathrm{Se}_{60}$ films studied in the terahertz spectral range at oblique $\left(75^{\circ}\right)$ incidence radiation showed characteristic bands related to $\mathrm{Sb}-\mathrm{Se}$ and $\mathrm{Ge}-\mathrm{Se}$ chemical bonds vibration in $\mathrm{SbSe}_{3}$ pyramidal and $\mathrm{GeSe}_{4}$ tetrahedral units, respectively. The peculiarities in the compositional dependences of the band positions and intensities confirm the existence of a topological phase transition in the $\mathrm{Ge}_{\mathrm{x}} \mathrm{Sb}_{40-\mathrm{x}} \mathrm{Se}_{60}$ glasses around a critical Ge content of $\mathrm{x}=27$ at.\%., corresponding to an average coordination number $\mathrm{Z}=2.67$.

\section{Data Availability}

The data used to support the findings of this study are available from the corresponding author upon request. 


\section{Conflicts of Interest}

The authors declare that they have no conflicts of interest.

\section{Acknowledgments}

The authors would like to thank Dr. Martin von Zimmermann for assistance in using BW5 beamline, under Hasylab Project No. I-20100116EC. The authors also acknowledge thanks to V. Pamukchieva for synthesizing the studied materials. The support from the Hungarian, Bulgarian, and Romanian Academies under the 2014-2017 Collaboration Agreements is highly appreciated. K. Antonova and A. Szekeres thank the European Regional Development Fund, Ministry of Economy of Bulgaria, Operational Programme "Development of the Competitiveness of the Bulgarian Economy" 2007-2013, Contract No. BG161PO003-1.2.04-0027-C0001, for purchasing the BRUKER spectrophotometer Vertex 70. N. Dulgheru and M. Gartner gratefully acknowledge the support of the research infrastructure under POS-CCEO 2.2.1 INFRANANOCHEM - project, No. 19/01.03.2009.

\section{References}

[1] J. A. Savage, Infrared Optical Materials and Their Antireflection Coatings, Bristol, UK, 1st edition, 1985.

[2] A. M. Andriesh, "Properties of chalcogenide glasses for optical waveguides," Journal of Non-Crystalline Solids, vol. 77-78, pp. 1219-1228, 1985.

[3] T. Kanamori, Y. Terunuma, S. Takahashi, and T. Miyashita, "Chalcogenide Glass Fibers for Mid-Infrared Transmission," Journal of Lightwave Technology, vol. 2, no. 5, pp. 607-613, 1984.

[4] G. G. Devyatykh and E. M. Dianov, "Research in KRS-5 and chalcogenide glass fibers," in Proceedings of the SPIE 0484, Infrared Optical Materials and Fibers III, vol. 484, pp. 105-107, 1984.

[5] Z. G. Ivanova, V. Pamukchiva, and M. Vlcek, "On the structural phase transformations in $\mathrm{Ge}_{x} \mathrm{Sb}_{40-x} \mathrm{Se}_{60}$ glasses," Journal of Non-Crystalline Solids, vol. 293-295, pp. 580-585, 2001.

[6] V. Pamukchieva, A. Szekeres, E. Savova, and E. Vlaikova, "Compositional dependence of the optical parameters of $\mathrm{Ge}_{x} \mathrm{Sb}_{40-x} \mathrm{Se}_{60}$ glasses," Journal of Non-Crystalline Solids, vol. 242, pp. 110-114, 1998.

[7] R. Svoboda, D. Brandová, and J. Málek, "Crystallization behavior of $\mathrm{GeSb}_{2} \mathrm{Se}_{4}$ chalcogenide glass," Journal of Non-Crystalline Solids, vol. 388, pp. 46-54, 2014.

[8] N. Sharma, S. Sharda, V. Sharma, and P. Sharma, "Farinfrared investigation of ternary $\mathrm{Ge}-\mathrm{Se}-\mathrm{Sb}$ and quaternary Ge-Se-Sb-Te chalcogenide glasses," Journal of Non-Crystalline Solids, vol. 375, pp. 114-118, 2013.

[9] A. K. Varshneya and D. Mauro, "Microhardness, indentation toughness, elasticity, plasticity, and brittleness of $\mathrm{Ge}-\mathrm{Sb}-\mathrm{Se}$ chalcogenide glasses," Journal of Non-Crystalline Solids, vol. 353, pp. 1291-1297, 2007.

[10] D. R. Goyal and A. S. Maan, "Far-infrared absorption in amorphous $\mathrm{Sb}_{15} \mathrm{Ge}_{x} \mathrm{Se}_{85-x}$ glasses," Journal of Non-Crystalline Solids, vol. 183, pp. 182-185, 1995.

[11] S. Y . Shin, J. M. Choi, J. Seo et al., "The effect of doping Sb on the electronic structure and the device characteristics of Ovonic Threshold Switches based on Ge-Se," Scientific Reports, vol. 4, 2014.
[12] P. Sharma, V. S. Rangra, P. Sharma, and S. C. Katyal, "Farinfrared study of amorphous $\mathrm{Ge}_{0.17} \mathrm{Se}_{0.83-x} \mathrm{Sb}_{x}$ chalcogenide glasses," Journal of Alloys and Compounds, vol. 480, pp. 934-937, 2009.

[13] S. Mahadevan and A. Giridhar, "Floppy to rigid transition and chemical ordering in $\mathrm{Ge}-\mathrm{Sb}(\mathrm{As})$-Se glasses," Journal of NonCrystalline Solids, vol. 143, pp. 52-58, 1992.

[14] K. Tanaka, "Structural phase transitions in chalcogenide glasses," Physical Review B: Condensed Matter and Materials Physics, vol. 39, no. 2, pp. 1270-1279, 1989.

[15] M. Fábián, E. Sváb, V. Pamukchieva, A. Szekeres, S. Vogel, and U. Ruett, "Study of $\mathrm{As}_{2} \mathrm{Se}_{3}$ and $\mathrm{As}_{2} \mathrm{Se}_{2} \mathrm{Te}$ glass structure by neutron- and X-ray diffraction methods," Journal of Physics: Conference Series, vol. 253, no. 1, Article ID 012053, 2010.

[16] V. Pamukchieva, A. Szekeres, K. Todorova, E. Svab, and M. Fabian, "Compositional dependence of the optical properties of new quaternary chalcogenide glasses of Ge-Sb-(S,Te) system," Optical Materials, vol. 32, pp. 45-48, 2009.

[17] V. Pamukchieva, A. Szekeres, K. Todorova et al., "Evaluation of basic physical parameters of quaternary $\mathrm{Ge}-\mathrm{Sb}-(\mathrm{S}, \mathrm{Te})$ chalcogenide glasses," Journal of Non-Crystalline Solids, vol. 355, pp. 2485-2490, 2009.

[18] M. Fabian, E. Svab, V. Pamukchieva et al., "Reverse Monte Carlo modeling of the neutron and X-ray diffraction data for new chalcogenide Ge-Sb-S(Se)-Te glasses," Journal of Physics and Chemistry of Solids, vol. 74, pp. 1355-1362, 2013.

[19] I. Pethes, R. Chahal, V. Nazabal et al., "Chemical Short-Range Order in Selenide and Telluride Glasses," The Journal of Physical Chemistry B, vol. 120, pp. 9204-9214, 2016.

[20] P. Kumar, V. Modgil, and V. S. Rangra, "The Far-Infrared Study of Ge Modified Sn-Se-Pb Chalcogenide Glasses," Journal of Non-Oxide Glasses, vol. 6, pp. 27-35, 2014.

[21] S. Sharda, N. Sharma, P. Sharma, and V. Sharma, "Finger prints of chemical bonds in $\mathrm{Sb}-\mathrm{Se}-\mathrm{Ge}$ and $\mathrm{Sb}-\mathrm{Se}-\mathrm{Ge}-\mathrm{In}$ glasses: A Far-IR study," Journal of Non-Crystalline Solids, vol. 362, pp. 136-139, 2013.

[22] E. Sváb, G. Mészáros, and F. Deák, "Neutron Powder Diffractometer at the Budapest Research Reactor," Materials Science Forum, vol. 228-231, pp. 247-252, 1996.

[23] H. Poulsen, J. Neuefeind, H. B. Neumann, J. R. Schneider, and M. D. Zeidler, "Amorphous silica studied by high energy X-ray diffraction," Journal of Non-Crystalline Solids, vol. 188, pp. 6374, 1995.

[24] A.C. Hannon, "ISIS Disordered Materials Database 2006," https:// www.isis.stfc.ac.uk/Pages/Disordered-Materials.aspx, (accessed 15 July 2018).

[25] D. Waasmaier and A. Kirfel, "New analytical scattering-factor functions for free atoms and ions," Acta Crystallographica, vol. 51, pp. 416-431, 1995.

[26] R. L. McGreevy and L. Pusztai, "Reverse Monte Carlo Simulation: A New Technique for the Determination of Disordered Structures," Molecular Simulation, vol. 1, pp. 359-367, 1988.

[27] O. Gereben, P. Jovari, L. Temleitner, and L. Pusztai, "A new version of the RMC++ Reverse Monte Carlo programme, aimed at investigating the structure of covalent glasses," Journal of Optoelectronics and Advanced Materials, pp. 3021-3027, 2007.

[28] V. Pamukchieva, "Private communication," 2015.

[29] M. A. Paesler, D. A. Baker, G. Lucovsky, A. E. Edwards, and P. C. Taylor, "EXAFS study of local order in the amorphous chalcogenide semiconductor $\mathrm{Ge}_{2} \mathrm{Sb}_{2} \mathrm{Te}_{5}$," Journal of Physics and Chemistry of Solids, vol. 68, pp. 873-877, 2007. 
[30] I. Petri, P. S. Salmon, and H. E. Fischer, "Defects in a Disordered World: The Structure of Glassy GeSe $e_{2}$," Physical Review Letters, vol. 84, pp. 2413-2416, 2000.

[31] F. Kakinuma, T. Fukunaga, and K. Suzuki, "Structural study of $\mathrm{Ge}_{x} \mathrm{Sb}_{40-x} \mathrm{~S}_{60}(\mathrm{x}=10,20$ and 30$)$ glasses," Journal of NonCrystalline Solids, vol. 353, pp. 3045-3048, 2007.

[32] L. Changgui, L. Zhuobin, Y. Lei et al., "Network Structure in $\mathrm{GeS}_{2}-\mathrm{Sb}_{2} \mathrm{~S}_{3}$ Chalcogenide Glasses: Raman Spectroscopy and Phase Transformation Study," The Journal of Physical Chemistry C, vol. 116, pp. 5862-5867, 2012.

[33] M. Fraenkl, B. Frumarova, V. Podzemna et al., "How silver influences the structure and physical properties of chalcogenide glass $\left(\mathrm{GeS}_{2}\right)_{50}\left(\mathrm{Sb}_{2} \mathrm{~S}_{3}\right)_{50}$," Journal of Non-Crystalline Solids, vol. 499, pp. 412-419, 2018.

[34] P. Jóvári, I. Kaban, J. Steiner, B. Beuneu, A. Schöps, and M. A. Webb, "Local order in amorphous $\mathrm{Ge}_{2} \mathrm{Sb}_{2} \mathrm{Te}_{5}$ and $\mathrm{GeSb}_{2} \mathrm{Te}_{4}$," Physical Review B: Condensed Matter and Materials Physics, vol. 77, Article ID 035202, 2008.

[35] M. T. M. Shatnawi, "Reverse Monte Carlo Modeling of the Rigidity Percolation Threshold in $\mathrm{Ge}_{x} \mathrm{Se}_{1-x}$ Glassy Networks," New Journal of Glass and Ceramics, vol. 5, no. 3, pp. 31-43, 2015.

[36] I. Quiroga, C. Corredor, F. Bellido, J. Vazquez, P. Villares, and R. J. Garay, "Infrared studies of a $\mathrm{Ge}_{0.20} \mathrm{Sb}_{0.05} \mathrm{Se}_{0.75}$ glassy semiconductor," Journal of Non-Crystalline Solids, vol. 196, pp. 183-186, 1996.

[37] W.-H. Wei, R.-P. Wang, X. Shen, L. Fang, and B. Luther-Davies, "Correlation between structural and physical properties in $\mathrm{Ge}$ Sb-Se glasses," The Journal of Physical Chemistry C, vol. 117, pp. 16571-16576, 2013.

[38] T. Ohsaka, "Infrared spectra of glassy Se containing small amounts of S, Te, As, or Ge," Journal of Non-Crystalline Solids, vol. 17, pp. 121-128, 1975.

[39] F. Verger, V. Nazabal, F. Colas et al., "RF sputtered amorphous chalcogenide thin films for surface enhanced infrared absorption spectroscopy," Optical Materials Express, vol. 3, pp. 21122131, 2013.

[40] E. Baudet, C. Cardinaud, A. Girard et al., "Structural analysis of RF sputtered Ge-Sb-Se thin films by Raman and X-ray photoelectron spectroscopies," Journal of Non-Crystalline Solids, vol. 444, pp. 64-72, 2016.

[41] Y. Chen, T. Xu, X. Shen et al., "Optical and structure properties of amorphous $\mathrm{Ge}-\mathrm{Sb}-\mathrm{Se}$ films for ultrafast all-optical signal processing," Journal of Alloys and Compounds, vol. 580, pp. 578583, 2013.

[42] A. M. Hofmeister, J. Horigan, and J. M. Campbell, "Infrared spectra of $\mathrm{GeO}_{2}$ with the rutile structure and prediction of inactive modes for isostructural compounds," American Mineralogist, vol. 75, pp. 1238-1248, 1990.

[43] G. S. Henderson, D. R. Neuville, B. Cochain, and L. Cormier, "The structure of $\mathrm{GeO}_{2}-\mathrm{SiO}_{2}$ glasses and melts: A Raman spectroscopy study," Journal of Non-Crystalline Solids, vol. 355, no. $8,2009$.

[44] N. Dulgheru, M. Gartner, M. Anastasescu et al., "Influence of compositional variation on the optical and morphological properties of $\mathrm{Ge}-\mathrm{Sb}-\mathrm{Se}$ films for optoelectronics application," Infrared Physics \& Technology, vol. 93, pp. 260-270, 2018. 

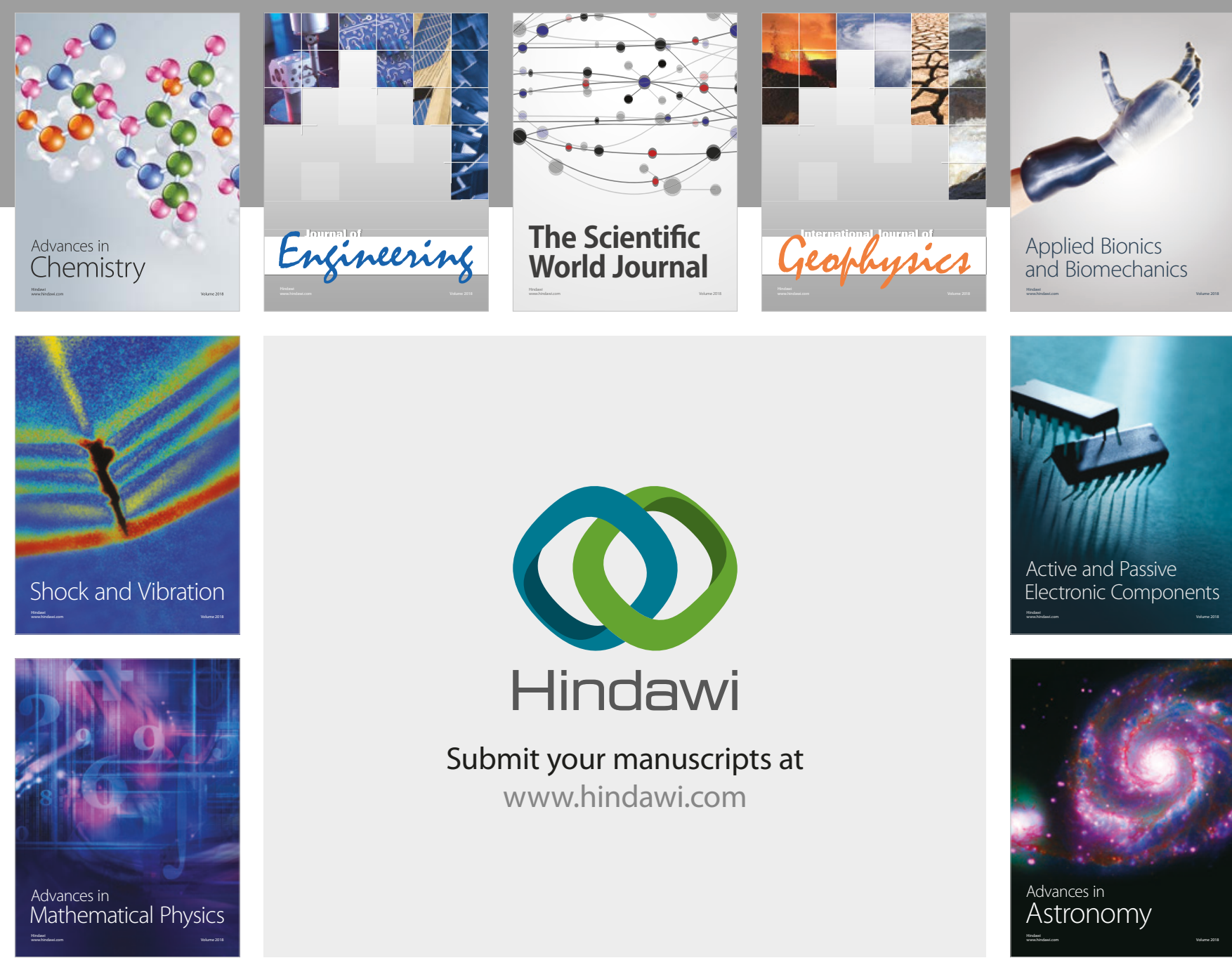

Submit your manuscripts at

www.hindawi.com

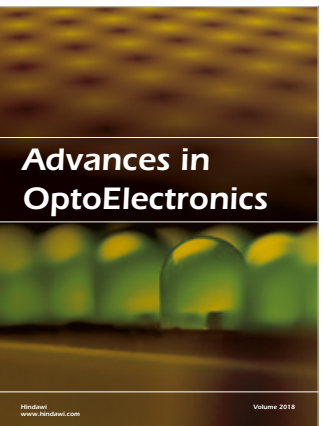

\section{Rotcting Machinery}
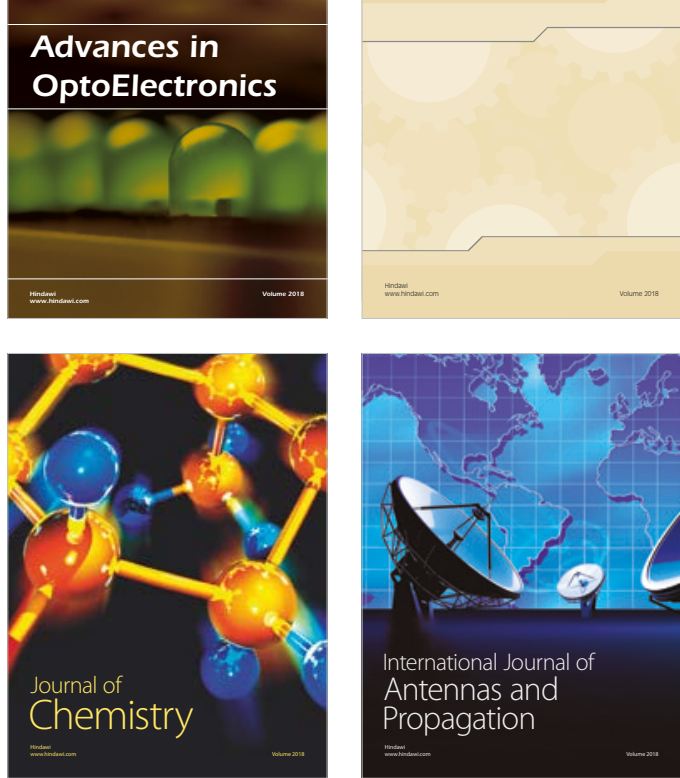

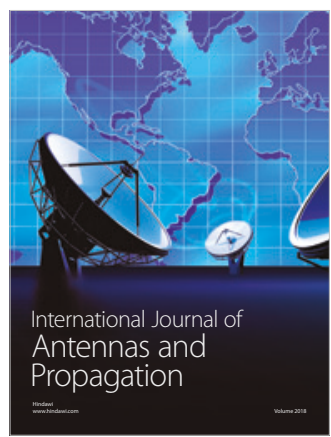

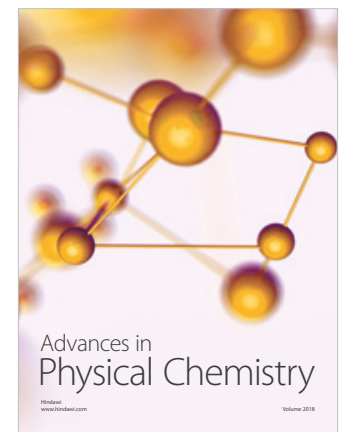

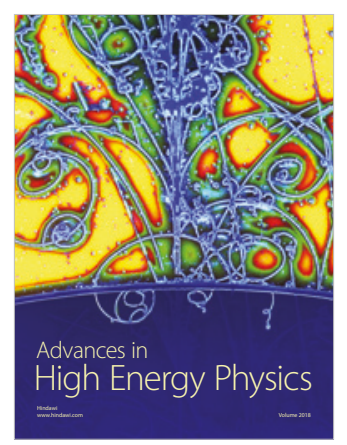

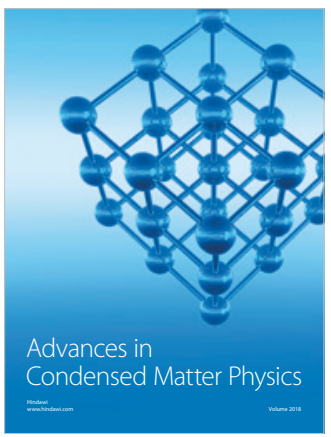

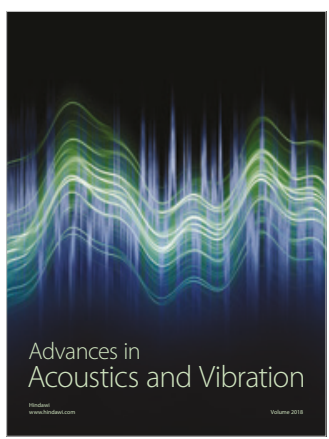

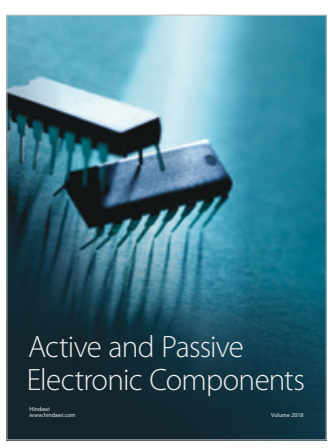
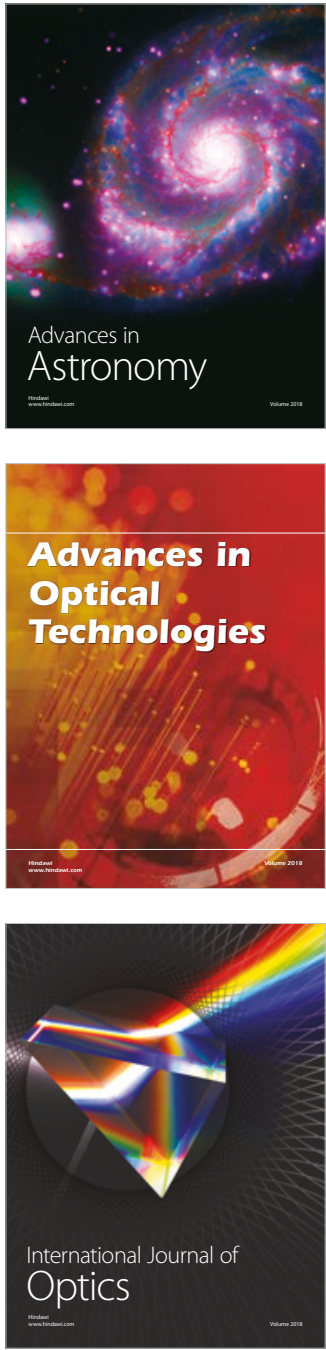